\title{
Younger breast cancer patients under the age of 35 might have a better disease-free survival if they received ovarian function suppression more than 3 years
}

\author{
Kadri Altundag ${ }^{1}$ (D) \\ Received: 27 May 2018 / Accepted: 25 July 2018 / Published online: 28 July 2018 \\ (c) The Japanese Breast Cancer Society 2018
}

To the Editor,

I want to congratulate Ozaki and colleagues [1] in which the authors evaluated the duration of ovarian function suppression (OFS) and the impact of the duration of OFS on the DFS in premenopausal women with hormone receptorpositive breast cancer. Their retrospective data showed that among premenopausal women with hormone receptor-positive breast cancer who received tamoxifen (TAM) + OFS as adjuvant endocrine therapy, there was no significant difference in the DFS between the OFS $\leq 3$-year group and OFS $>3$-year group. NCCN guidelines commonly recommend 5 years of aromatase inhibitors with ovarian suppression, especially for younger patients under the age of 35 . NCCN guidelines also commonly recommend tamoxifen and ovarian suppression [2]. However, duration of OFS was not optimally described. International expert consensus favored a period of 5 years of OFS, especially in patients at higher risk of relapse such as younger age $(\leq 35)$ and/ or with HER2-positive disease [3]. The authors evaluated DFS of the patients referencing age 40. As described above, DFS might shift better in breast cancer patients younger

This comment refers to the article available online at https://doi. org/10.1007/s12282-018-0836-x.

Kadri Altundag

altundag66@yahoo.com

1 MKA Breast Cancer Clinic, Tepe Prime, Ankara 06800,

Turkey than age 35 who received OFS $>3$-year group. Since study by Ozaki et al. [1] compared the patients according to age above 40 and age $\leq 40$, significant benefit of OFS $>3$-year group might not have been detected. Therefore, evaluation of DFS referencing age 35 might show potential benefit of OFS $>3$-year group in patients age $\leq 35$ in the current study.

\section{Compliance with ethical standards}

Conflict of interest I have no conflict of interest to declare.

\section{References}

1. Ozaki Y, Tanabe Y, Tamura N, Ogura T, Kondoh C, Miura Y, et al. Impact on disease-free survival of the duration of ovarian function suppression, as postoperative adjuvant therapy, in premenopausal women with hormone receptor-positive breast cancer: a retrospective single-institution study. Breast Cancer. 2018;25:343-9.

2. https://www.nccn.org/professionals/physician_gls/pdf/breast.pdf. Accessed 27 May 2018.

3. Goldhirsch A, Wood WC, Gelber RD, Coates AS, Thürlimann B, Senn HJ, 10th St. Gallen conference. Progress and promise: highlights of the international expert consensus on the primary therapy of early breast cancer 2007. Ann Oncol. 2007;18:1133-44. 